Rizk L., Hamzeh F., and Emdanat S. (2017). "Introducing New Capacity Planning Metrics in Production Planning." In: LC3 2017 Volume II - Proceedings of the 25th Annual Conference of the International Group for Lean Construction (IGLC), Walsh, K., Sacks, R., Brilakis, I. (eds.), Heraklion, Greece, pp. 679686. DOI: https://doi.org/10.24928/2017/0203

\title{
INTRODUCING NEW CAPACITY PLANNING METRICS IN PRODUCTION PLANNING
}

\author{
Lynn Rizk ${ }^{1}$, Farook Hamzeh ${ }^{2}$, and Samir Emdanat ${ }^{3}$
}

\begin{abstract}
The need for proper and reliable planning is essential for project success. Capacity planning has received good attention in the construction community but few metrics exist to assess its performance. Since it is impossible to improve what cannot be measured, the goal of this paper is to introduce new capacity planning metrics that will help visualize and understand the current state of capacity planning on construction projects. Is there an overloading or under loading of resources? The new metrics developed in this research, will attempt to help in assessing the state of equilibrium in choosing the weekly load of tasks to match the existing capacity, or at least, to minimize the gap between the two as much as possible. These new metrics, in theory, will achieve the goal of informing planners and last planners about the status of load vs. capacity, the matching between the two, and the reliability of capacity planning on a project.
\end{abstract}

Keywords: Last Planner System ${ }^{\mathrm{TM}}$, lean construction, planning and scheduling, capacity planning, capacity planning metrics, matching load to capacity.

\section{INTRODUCTION}

Planning is an essential step in managing production flow on a project. If the proper time and resources are adequately allocated to planning efforts, the probability of success of the project will increase. Furthermore, much of the risk, that may not have been perceived prior to planning, can be greatly reduced (Aziz and Hafez, 2013). The investment in defining and developing the scope of the project, the requirements, and technical specifications have a positive impact on the success of a project (Dvir, Raz and Shenhar, 2003). But although planning is very crucial at early project stages, ongoing planning during production which includes capacity planning is instrumental in shaping production; and thus worth studying.

A lot of research has gone into understanding the planning and the scheduling of tasks from a chronological point of view, but there is also the planning of how to assign the activities and tasks (the load) to the available labour, equipment, and resources (the available capacity). This is known as capacity planning. With this new face of planning comes another dimension to the problem of planning and scheduling, which is the issue of matching load to capacity. How many of the activities should we allocate to the labour? How much work can the labour force accommodate at a time? Is there an optimum ratio between load and capacity? It is important to study the balance problem between load and capacity. Allocating adequate time and resources to planning is only one solution to the problem, but it cannot contribute to the success of the project if there is a mismatching

1 Graduate Student, Civil and Environmental Engineering Department, American University of Beirut, Beirut, Lebanon, lar07@mail.aub.edu

2 Assistant Professor, Civil and Environmental Engineering Department, American University of Beirut, Beirut, Lebanon, + 9611350000 Ext. 3616, fax: + 9611 744462, Farook.Hamzeh@aub.edu.lb

3 Director of Management Services, Ghafari Associates, LLC, 17101 Michigan Avenue, Dearborn, Michigan 48126, semdanat@ghafari.com 
problem between capacity and load. Therefore, it is important to understand the relationship between capacity and load and to have the adequate metrics to assess the status of resource allocation in an attempt to figure out how to strike a proper balance between the two.

\section{LITERATURE REVIEW}

\subsection{Project Planning}

The level of planning and effort exerted on a construction project highly affects the extent of the success of the project (Abbas, Ud Din and Farooqui, 2016). The upper third of projects, when it comes to completeness of planning, had an $82 \%$ chance of meeting their budget goals (Hamilton and Gibson, 1996). This leads to the question of how much planning is enough planning?

Research suggests that not enough time is allocated to properly plan for the average project. Furthermore, the effort put into the planning phase was found to have the strongest relationship with the overall project success. When the level of effort during the planning phase is reduced, final value to customers, stakeholders, and the company is also reduced. On the other hand, projects with planning phases that are too long had low success ratings, similar to the projects with short planning durations low and planning efforts (Serrador and Turner, 2015).

\subsection{Task Planning}

Different stages of the project require different levels of planning effort and control. Planning is performed from a long-term perspective first, and from a short-term perspective later on. The long-term planning phase is where the major project milestones are set, after which the milestones are broken down into phases. Later, short-term planning starts, where 6-week look-ahead plans are set, that are then broken down to weekly work plans. Therefore, planning is performed in greater detail the closer we get to start the activity (Hamzeh and Langerud, 2011). Similarly, a task that is planned in this way will have fulfilled the objectives and requirements it sought out to fulfil when it is executed and completed.

Planning involves several aspects including cost, scheduling, quality, and making sure that the prerequisites of the task are well-defined and available (Hamzeh, Zankoul and Rouhana, 2015). Additionally, an important step in task planning is the analysis of the potential problems that might arise (a what-if analysis) (Junnonen and Seppanen, 2004). After all, the emergence of problems is largely due to the existence of unforeseen circumstances and the presence of variability.

Furthermore, due to the dynamic and uncertain nature of construction projects, there are always "new" tasks that emerge during the week which they are to be executed. These are the tasks that are "not included in the weekly schedule or are included in it but are allocated within the wrong time frame." (Rouhana and Hamzeh, 2016). Thus, these "new tasks", are activities that were not part of the initial plan and task breakdown but have now appeared as activities that need to be executed for the completion of the project.

\subsection{Variability}

Variability is a fact of life that. It is ubiquitous, and the field of construction is no exception. Ben-Haim and Laufer distinguish between two types of uncertainty. It can either be structured, which is the usual year to year variation of the weather, or unstructured which 
is "a substantial information-gap between what we do know and what we need to know to perform optimally" (Ben-Haim and Laufer, 1998). Furthermore, variability negatively affects the many aspects of project performance and "leads to ineffective production, increased cycle times, increased cost, and derailed plans" (Gupta, Gonzalez and Miller, 2012).

When it comes to construction projects, variability can be detected in factors such as the production rate, the productivity of labour, and the schedules of construction (Gonzalez, Alacron and Molenaar, 2009). Uncertainty and/or variability have been acknowledged as reasons for poor construction project performance (Ballard and Howell, 1998). Moreover, the Parade Game was created to illustrate how variability impacts performance and production. It can be concluded that variability and unreliable work flow cause a decrease in throughput, a delayed completion date for the project, and an increase in waste (where some production phases do not use their full output capacity because "they starve for resources") (Tommelein, Riley and Howell, 1998).

\subsection{Matching Load to Capacity}

So far, the dynamics of variability, in the field of construction, have not been completely understood. Therefore, planners often fall into the problem of matching load to capacity which is not an easy task to achieve. Ballard defines load as the quantity of work needed to be done in a specific time allotted by planners, and capacity is the quantity of work a crew can complete given their tools, methods of work, and conditions on-site (Ballard 2000). When load and capacity estimates are different from the actual measurements, the planning crew must either alter load to match capacity by postponing or fast-tracking work flow, alter capacity to meet load by changing the quantity of resources, or an amalgamation of both (Gonzalez et al., 2010).

Production planning endeavours to match load to capacity with top accuracy based on given circumstances (Ballard et al., 2007). Thus, production planners require information regarding workloads and resource capacity (Kim and Kim, 2012). Kim et al. (2008) came up with a workforce information (level of skill, history of accidents, etc.) database to help solve the problem of matching load to capacity. "The workforce database system allows the user to consider workforce capacity in production planning" (Kim et al. 2008).

Despite the plethora of research on the importance of matching load (tasks put on the weekly work plan) to capacity (available resources), no clear metrics were derived to assess capacity planning in conjunction with the Last Planner System (LPS). This study proposes six metrics to assess the performance of capacity planning to guides last planner in managing and controlling production and workflow.

\section{Methodology}

Planners cannot manage what they cannot measure. Furthermore, measurement cannot happen without having proper metrics. In some instances, construction companies are overloading their resources and sometimes the resources are not being efficiently employed. Thus, the need for metrics, to help us better visualize how we are loading our resources, arises. Furthermore, we realize that there are not enough metrics in the field of planning that aid in adequately describing the state of capacity planning on a certain project. Accordingly, in an effort to better understand and attempt to find a proper solution to the problem of matching load to capacity, we devised six metrics that will serve as being somewhat descriptive of the state of planning on a project in general, and capacity planning in particular. 
Before coming up with the metrics discussed in this paper, this study distinguishes between three types of activity clusters as shown in figure 1 . Within each cluster, there are two colours, red and green. The green pebbles represent normal activities while the red pebbles represent required activities (i.e. critical activities).

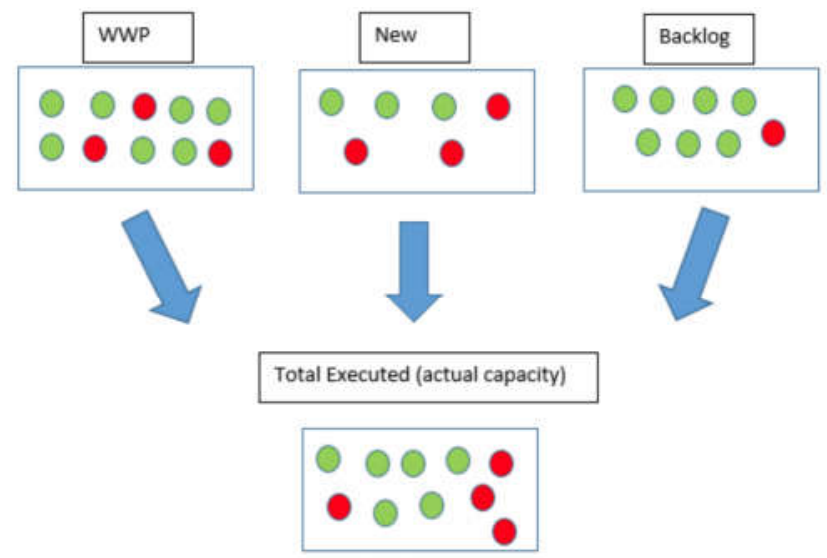

Figure 1 - Activity Clusters

The first cluster, as depicted in Figure 1, is the WWP cluster, where WWP stands for Weekly Work Plan. This group of activities consists of all the tasks that have been committed to be completed that week. The second cluster of activities is called New which are tasks that need to be executed during the week as pre-requisites or co-requisites to other tasks. Notice also that some tasks are required, in other words critical, (red) while others are not (green). The third cluster, Backlog, is representative of the activities that make up the backlog. These are the activities that are assigned when the team has completed the activities that they have committed to complete and they have extra resources to work more.

Furthermore, Figure 1 shows a fourth cluster of activities, Total Executed, which is the actual activities that have been executed that week (i.e. the actual capacity). The three clusters mentioned above contribute to the Total Executed cluster of activities. The tasks that have been executed in that week constitute the actual capacity and the tasks that have been chosen to be on the weekly work plan are the chosen load.

\section{RESULTS AND DISCUSSION}

\subsection{Results}

Six new metrics were created as described below. Note that these metrics are to be used for measurement on a weekly basis when applying the LPS.

The first metric is called the Capacity to Load Ratio (CLR). This metric is a comparison of the chosen load with the actual capacity. It is calculated by dividing the total number of activities executed this week by the number of activities on the weekly work plan (WWP), i.e. the activities the team has committed to completing this week. It is a retrospective metric which aids in tracking how close the team is in adequately employing resources. The CLR is calculated using equation (1) below.

$$
C L R=\frac{\text { Total Executed }}{W W P}
$$


The second metric is the CLR man-hrs. It is the same as the CLR described above with one difference; the CLR calculated in equation (1) is at the level of activities while the CLR man-hrs is at the level of the man-hours required to complete the activities. It is calculated by dividing the quantity of man-hours it took to complete the activities that have been executed this week by the quantity of man-hours required to complete the activities committed on the WWP. The CLR man-hrs is calculated using equation (2) below.

$$
\text { CLR man }- \text { hrs }=\frac{\text { Actual man }- \text { hours }}{\text { WWP man }- \text { hours Worked }}
$$

The third metric is called the Required Capacity Ratio (RCR) which represents the fraction of completed activities that are required (i.e. activities that are critical). It is calculated by dividing the required activities that were completed by the total number of activities that were executed, as shown in equation (3) below.

$$
R C R=\frac{\text { Required Executed }}{\text { Total Executed }}
$$

The fourth metric is called the Required Percent Complete (RPC) which represents the percentage of required tasks that have been completed. It is calculated by dividing executed required activities by the total critical activities this week, as shown in equation (4) below.

$$
R P C=\frac{\text { Required Executed }}{\text { Total Required }}
$$

The fifth and sixth metric are complementary and related. They are both used to assess the deviation from the WWP. The Weekly Deviation (WD) gives us an indication of how far the team has deviated from the WWP, and the direction of the deviation (i.e. if $\mathrm{WD}<0$ then the team is under loading their resources, if $W D>0$ then then the team is overloading their resources, and if $\mathrm{WD}=0$ then then the team has matched the load to capacity). The Weekly Deviation Ratio (WDR) is the WD normalized by the WWP for comparison purposes. The WD and the WDR are each calculated by using equations (5) and (6) respectively.

$$
\begin{gathered}
W D=W W P-\text { Total Executed } \\
W D R=\frac{W W P-\text { Total Executed }}{W W P}
\end{gathered}
$$

Table 1 summarizes all the metrics with their respective equations and descriptions, and Table 2 lists the variables required to calculate these metrics.

\subsection{Examples and Discussion}

To describe the use of the metrics suggested in this study, sample calculations were developed. The following examples serve to help the reader understand the application and the importance of the newly introduced metrics. The data summarized in Table 3 is used as input for the metric calculations that follow. The data is assumed to capture the capacity planning data comparing commitment planning to actual data at the end of the week. Note that activities with an asterisk sign $\left({ }^{*}\right)$ are required activities. 
Table 1 - New Capacity Planning Metrics

\begin{tabular}{|c|c|c|}
\hline Metric & Formula & Description \\
\hline $\begin{array}{l}\text { Capacity to Load } \\
\text { Ratio }\end{array}$ & $\frac{\text { Total Executed }}{W W P}$ & $\begin{array}{l}\text { Number of executed activities vs. } \\
\text { number of committed activities. }\end{array}$ \\
\hline $\begin{array}{l}\text { Capacity to Load } \\
\text { Ratio man-hrs }\end{array}$ & $\frac{\text { Actual man - hours }}{\text { WWP man - hours Worked }}$ & $\begin{array}{l}\text { How many man hours have actually } \\
\text { been expended vs. the hours } \\
\text { required to complete the WWP. }\end{array}$ \\
\hline $\begin{array}{l}\text { Required Capacity } \\
\text { Ratio }\end{array}$ & $\frac{\text { Required Executed }}{\text { Total Executed }}$ & $\begin{array}{l}\text { From the total executed tasks for } \\
\text { that week, how many required. }\end{array}$ \\
\hline $\begin{array}{l}\text { Required Percent } \\
\text { Complete }\end{array}$ & $\frac{\text { Required Executed }}{\text { Total Required }}$ & $\begin{array}{l}\text { Out of all required tasks for this } \\
\text { week, how many have been } \\
\text { executed. }\end{array}$ \\
\hline Weekly Deviation & $W W P-$ Total Executed & $\begin{array}{l}\text { How far from the WWP we have } \\
\text { deviated and in what direction. }\end{array}$ \\
\hline $\begin{array}{l}\text { Weekly Deviation } \\
\text { Ratio }\end{array}$ & $\frac{W W P-\text { Total Executed }}{W W P}$ & Normalized WD for comparison. \\
\hline
\end{tabular}

Table 2 - Variables included in the calculation of metrics

\begin{tabular}{|c|c|c|c|c|c|}
\hline Variables & \multicolumn{5}{|c|}{ Description } \\
\hline WWP & \multicolumn{5}{|c|}{$\begin{array}{l}\text { Weekly Work Plan, i.e. the activities on the weekly work plan } \\
\text { that have been committed to be completed for that week. }\end{array}$} \\
\hline WWP man-hours & \multicolumn{5}{|c|}{$\begin{array}{c}\text { The quantity of man-hours required to complete all the activities } \\
\text { on the weekly work plan for that week. }\end{array}$} \\
\hline $\begin{array}{l}\text { Actual man-hours } \\
\text { Worked }\end{array}$ & \multicolumn{5}{|c|}{$\begin{array}{l}\text { The quantity of man-hours that was actually expended that weel } \\
\text { to execute the activities that were actually completed. }\end{array}$} \\
\hline Required Executed & \multicolumn{5}{|c|}{$\begin{array}{l}\text { The critical activities that were executed that week (i.e. all red } \\
\text { circles in Total Executed Cluster). }\end{array}$} \\
\hline Total Executed & \multicolumn{5}{|c|}{$\begin{array}{l}\text { The activities that were actually executed that week (i.e. all } \\
\text { circles in Total Executed cluster). }\end{array}$} \\
\hline Total Required & \multicolumn{5}{|c|}{$\begin{array}{c}\text { The critical activities that are on the WWP, the backlog, and the } \\
\text { new required activities for that week (i.e. all red circles in the } 3 \\
\text { clusters). }\end{array}$} \\
\hline \multicolumn{6}{|c|}{ Table 3 - Sample Data for a Week $\left(\left(^{*}\right)\right.$ stands for required activities) } \\
\hline Activities & $A^{*}$ & B & $\mathrm{C}^{*}$ & $\mathrm{D}$ & $E^{*}$ \\
\hline Man - hrs/activity & 100 & 200 & 250 & 150 & 300 \\
\hline \% Comp. (actual) & $100 \%$ & $19 \%$ & $7 \%$ & $100 \%$ & $3 \%$ \\
\hline \% Comp. (WWP) & $100 \%$ & $100 \%$ & $100 \%$ & $0 \%$ & $0 \%$ \\
\hline
\end{tabular}




\subsubsection{CLR and CLR man - hrs}

$$
C L R \text { man }-h r s=\frac{(1 * 100)+(0.19 * 200)+\cdots+(0.03 * 300)}{100+200+250}=0.57
$$

Considering CLR alone, which yielded a value of $67 \%$, it can be said that the team was somewhat close to matching the load to available capacity. But looking at both CLR and CLR man-hrs, the latter yielding a value smaller than the former, shows that analysing activities is not enough. Measuring CLR in terms of man-hrs can show a different angle to that of CLR. Thus, both metrics are required to properly assess resource/task allocation.

\subsubsection{RCR and RPC}

$$
R C R=1 / 2=0.50, \quad R P C=1 / 3=0.33
$$

RCR yields a value of 0.5 , which means that $50 \%$ of all executed tasks this week are required. Alternatively, RPC yields a value of 0.33 which means that $33 \%$ of required tasks have been completed. If we look at RPC alone, it raises the question of why has only a percentage of the required tasks been executed. Has the team wrongly allocated capacity or have the constraints for these tasks not been removed? Here, we can look at RCR. Since RCR yielded a value different than one, this means that part of the allocation of resources went to completing tasks that were not required. Thus, from these two metrics, last planners can assess if they are adequately allocating their resources to made ready tasks.

\subsubsection{WD and WDR}

$$
W D=3-2=1, \quad W D R=(3-2) / 3=0.33
$$

In this sample calculation, WD yielded a positive value, which indicates that the team has over committed, thus overloading the available resources $(\mathrm{WD}>0$, which means that WWP $>$ Total Executed). Furthermore, notice that WDR is less than 1. This metric can be used for comparison across weeks and across projects.

\section{CONCLUSION}

The need for proper and reliable planning is essential for project success. Capacity planning has received good attention in the construction community but few metrics exist to assess its performance. The new metrics introduced in this paper will help in informing planners and last planners about the status of load vs. capacity, the matching between the two, and the reliability of capacity planning on a project.

Six metrics related to capacity planning, to be calculated on a weekly basis, were introduced in this study. The CLR (capacity to load ratio) measures the capacity available (tasks actually completed) versus the chosen load (tasks committed to be completed that week); the CLR man-hrs is the same as the previous metric except that it measures manhours (i.e. man-hours actually expended vs. man-hours required to complete the committed tasks). The third metric is RCR which gives the planners an indication of how many tasks were required out of all those executed this week, and the fourth metric is RPC which depicts the percentage of required tasks completed this week. The last two metrics are WD which is deviation from the WWP, and WDR which is the normalized version of the WD (for comparison across multiple weeks and/or across different projects).

Further research on this topic and the testing of these metrics to prove their reliability in attempting to visualize the problem of capacity planning, is required. The authors are in the process of applying these metrics on actual projects to assess their utility and highlight major issues in capacity planning. 


\section{REFERENCES}

Abbas, A., Ud Din, Z. and Farooqui, R. (2016). Achieving Greater Project Success \& Profitability through Pre-Construction Planning: A Case-based Study. In: ICSDEC 2016-Integrating Data Science, Construction and Sustainability. Procedia Engineering, pp.804-811.

Aziz, R. and Hafez, S. (2013). Applying lean thinking in construction and performance improvement. Alexandria Engineering Journal, 52(4), pp.679-695.

Ballard, G. (2000). The Last Planner System of Production Control. Ph.D. University of Birmingham.

Ballard, G. and Howell, G. (1998). Shielding Production: Essential Step in Production Control. Journal of Construction Engineering and Management, 124(1), pp.11-17.

Ballard, G., Kim, Y., Jang, J. and Liu, M. (2007). Roadmap to Lean Implementation at Project Level. Research Report 234-11. Austin, Texas: Construction Industry Institute, The University of Texas at Austin.

Ben-Haim, Y. and Laufer, A. (1998). Robust Reliability of Projects with Activity-Duration Uncertainty. Journal of Construction Engineering and Management, 124(2),pp.125-132.

Dvir, D., Raz, T. and Shenhar, A. (2003). An empirical analysis of the relationship between project planning and project success. International Journal of Project Management, 21(2), pp.89-95.

González, V., Alarcón, L. and Molenaar, K. (2009). Multiobjective design of Work-InProcess buffer for scheduling repetitive building projects. Automation in Construction, 18(2), pp.95-108.

González, V., Alarcón, L., Maturana, S., Mundaca, F. and Bustamante, J. (2010). Improving Planning Reliability and Project Performance Using the Reliable Commitment Model. Journal of Construction Engineering and Management, 136(10), pp.1129-1139.

Hamilton, M. and Gibson, G. (1996). Benchmarking Preproject Planning Effort. Journal of Management in Engineering, 12(2), pp.25-33.

Hamzeh, F. and Langerud, (2011). Using Simulation to Study the Impact of Improving Lookahead Planning on the Reliability of Production Planning. In: The 2011 Winter Simulation Conference. pp. 3436-3447.

Hamzeh, F. R., Zankoul, E., and Rouhana, C. (2015) "How can 'tasks made ready' during lookahead planning impact reliable workflow and project duration?" Construction Management and Economics, Taylor and Francis, pp 243-258

Junnonen, J. and Seppanen, O. (2004). Task Planning as a Part of Production Control. In: 12th Annual Conference of the International Group for Lean Construction. pp. 1-11.

Kim, S. and Kim, Y. (2012). Workforce information database system to support production planning in construction projects. Journal of Civil Engineering and Management, 18(6), pp.867-878.

Kim, S., Kim, Y. and Park, C. (2008). Introduction of Workforce Database System for Effective Production Planning. In: The 16th Annual Conference of the International Group for Lean Construction. pp. 833-838.

Rouhana, C. and Hamzeh, F. (2016). An ABC Approach to Modelling the Emergence of 'New Tasks' in Weekly Construction Planning. Lean Construction Journal, pp.35-56.

Serrador, P. and Turner, R. (2015). What is Enough Planning? Results from a Global Quantitative Study. IEEE Transactions on Engineering Management, 62(4), pp.462-474.

Tommelein, I., Riley, D. and Howell, G. (1998). Parade Game: Impact of Work Flow Variability on Succeeding Trade Performance. In: The 6th Annual Conference of the International Group for Lean Construction. 